\title{
Trends and Outcomes in the Treatment of Gliomas Based on Data during 2001-2004 from the Brain Tumor Registry of Japan
}

\author{
Yoshitaka NARITA, ${ }^{1}$ Soichiro SHIBUI'2; On Behalf of the Committee of Brain \\ Tumor Registry of Japan Supported by the Japan Neurosurgical Society
}

\author{
${ }^{1}$ Department of Neurosurgery and Neuro-Oncology, National Cancer Center Hospital, Tokyo; \\ ${ }^{2}$ Department of Neurosurgery, Teikyo University School of Medicine University Hospital, \\ Kawasaki, Kanagawa
}

\begin{abstract}
The committee of Brain Tumor Registry of Japan (BTRJ) was founded in 1973 and conducts surveys and analyses of incidence, therapeutic methods, and treatment outcomes of primary and metastatic brain tumors with the cooperation of the Japan Neurosurgical Society members. Newly diagnosed 3,000-4,000 primary brain tumors and 600-1,000 brain metastases patients were enrolled in each year. This report describes the trends and treatment outcomes of gliomas from BTRJ volume 13, including 13,431 patients with primary brain tumors who newly started treatment from 2001 to 2004. Data from 382 diffuse astrocytomas (DAs), 121 oligodendrogliomas (OLs), 90 oligoastrocytomas (OAs), 513 anaplastic astrocytomas (AAs), 126 anaplastic oligodendrogliomas (AOs), 106 anaplastic oligoastrocytomas (AOAs), and 1,489 glioblastomas (GBMs) were analyzed for overall survival (OS) and progression free survival (PFS) depending on age, symptoms, Karnofsky performance status, location of the tumor, extent of resection (EOR), initial radiotherapy and chemotherapy. The 5-year PFS rates of the patients with DA, OL + OA, AA, AO + AOA, and GBM were $57.0 \%, 74.6 \%, 28.7 \%, 54.0 \%$, and $9.2 \%$, and the 5 -year $\mathrm{OS}$ rates were $75.0 \%, 90.0 \%, 41.1 \%$, $68.2 \%$, and $10.1 \%$, respectively. Higher EOR $\geq 75 \%$ in DA and $\mathrm{OL}+\mathrm{OA}$ and that $\geq 50 \%$ in $\mathrm{AA}, \mathrm{AO}+\mathrm{AOA}$, and GBM significantly prolonged OS. Complications and cause of death were also reported. BTRJ had been edited for all the patients, researchers, and especially for clinicians at bedside to give useful information about brain tumors and to contribute to the advances in brain tumor treatment. This report revealed various clinical problematic issues pertaining to the diagnosis and treatment of gliomas.
\end{abstract}

Key words: brain tumor registry, glioma, glioblastoma, astrocytoma, oligodendroglioma

\section{History of Brain Tumor Registry of Japan}

The committee of Brain Tumor Registry of Japan (BTRJ) was founded by Professors Keiji Sano and Kintomo Takakura in 1973. The previous chairman of BTRJ were Prof. Sano Keiji, Takakura Kintomo, and Nomura Kazuhiro and the current chairman is Shibui S. To contribute to advances in brain tumor treatment, the BTRJ has been used to investigate the current status of brain tumor incidence, therapeutic methods, and treatment outcomes. From the beginning, data have been registered as a result of collaboration among approximately 300 institutions; the first volume of information, which described

Received October 8, 2014; Accepted January 5, 2015 data from 1969 to 1974 , was issued in 1977 by the BTRJ. ${ }^{1)}$ For patients with major brain tumors that were first treated in 1969, namely diffuse astrocytomas (DAs), glioblastomas (GBMs), meningiomas, pituitary adenomas, and neurinomas, the 5-year survival rates were $27.3 \%, 1.7 \%, 40.8 \%, 43.2 \%$, and $31.1 \%$, respectively, showing rates $<50 \%$ even for benign brain tumors. ${ }^{1)}$ The BTRJ is issued every few years; thus far, a total of 13 volumes have been published. In 1992, the BTRJ started to publish its data in the journal Neurologia medico-chirurgica. ${ }^{2-7)}$

In 2004, the committee of BTRJ was placed under control of the Scientific Advisory Committee of the Japan Neurosurgical Society (JNS) and has continued conducting surveys and analyses with the cooperation of the JNS members. Among the approximately 1,000 institutions that employ JNS 
members, 200-300 institutions participated and $3,000-4,000$ primary brain tumors and $600-1,000$ brain metastases patients who newly started treatment were enrolled in each year. Regarding data obtained between 1973 and 2000, paper-based questionnaires were distributed to the JNS-certified facilities. The following data were collected and analyzed at the BTRJ office in the Department of Neurosurgery, National Cancer Center: patients' information such as place and date of birth; name and site of the brain tumor; therapeutic method; and treatment outcome. Data obtained in and after 2001 were registered online using the University Hospital Medical Information Network (UMIN)/ Internet Data and Information Center for Medical Research system (INDICE) at the University of Tokyo, and volume 13 was issued in 2014. ${ }^{7)}$ In volume 13, patients who had been under treatment for 5 years and more were included, and the pathological diagnosis, patient backgrounds, clinical diagnosis, treatment content, and therapeutic outcomes were registered online starting in 2009 on the basis of existing linkable anonymized data. All data were analyzed using Microsoft Excel VBA (Microsoft Corporation, Redmond, Washington, USA), SAS version 9.3, and JMP version 8 (SAS Institute Inc., Cary, North Carolina, USA) at the Department of Mathematics, Tokyo University of Science, Shinjuku, Tokyo. Survival time was calculated using the Kaplan-Meier method. Based on the 2007 World Health Organization Classification of Tumours of the Central Nervous System, ${ }^{8}$ all primary and metastatic brain tumor patients' ages, genders, median overall survival (OS), and median progression free survival (PFS) were listed, and the median OS/PFS of the 25 most frequent types of brain tumors were listed according to the initial symptoms, treatment modality, and age. This survey and research was performed based on ethical guidelines for epidemiology research 2008 and approved by the internal board by the National Cancer Center.

\section{Estimate of the Number of Gliomas in Japan}

Although the exact number of patients with primary brain tumors in Japan remains unclear, it is estimated to be approximately 20,000 people per year. In a survey conducted from 1989 to 2008 in Kumamoto Prefecture (Japan), reports on brain tumors from 5,448 patients were gathered and showed that the incidence of brain tumors was 14.1 people per 100,000 population. ${ }^{9)}$ According to a survey on brain tumors in the United States (US) ${ }^{10)}$ conducted from 2005 to 2009 and in the Republic of Korea in 2010, ${ }^{11)}$ the incidences of primary brain tumors in the US and Republic of Korea were 20.59 and 20.06 per year per 100,000 . Due to the increasing number of elderly people and the fact that asymptomatic brain tumors can be diagnosed on the basis of computed tomography/magnetic resonance imaging findings, the incidence of primary brain tumors has been gradually increasing. The incidence of meningiomas per 100,000 population was 7.49 , that of gliomas was 6.60 , that of pituitary adenomas was 2.94 , that of neurinomas was 1.70 , and that of primary central nervous system lymphomas was $0.46 .{ }^{10)}$ The incidence of brain tumors in Kumamoto when classified by histological type was the same as that found in the US. A simple calculation based on data from Kumamoto prefecture ${ }^{9)}$ and the US, ${ }^{10)}$ as well as on the Japanese population of 127 million in 2013, would show the following equation: 127 million people $\times 14.1-20.59 / 100,000$ people $=$ 18,000-25,000 people. Thus, the number of patients with primary brain tumors in Japan is estimated to be approximately 20,000 per year. The registration of all cancer cases is scheduled to begin in Japan as well in 2016 and the exact number of brain tumor patients will be shown.

In BTRJ volume 13 (2001-2004), ${ }^{7)}$ 13,431 cases of primary brain tumors were registered, most from university hospitals in Japan, and gliomas were the most frequently encountered. Assuming that there are 20,000 patients with primary brain tumors in Japan, the annual number of occurrences of major types of gliomas is estimated to account for 287 patients with pilocytic astrocytoma (PA), 569 patients with DA, and 314 patients with oligodendroglial tumors, which include oligodendrogliomas (OLs) and oligoastrocytomas (OAs), 764 anaplastic astrocytomas (AAs), 314 anaplastic oligodendroglial tumors, which include anaplastic oligodendroglioma (AO) and anaplastic oligoastrocytoma (AOA), 2,217 GBMs, 107 ependymomas, and 82 anaplastic ependymomas.

This report mainly describes grades II-IV of the DA, OL, OA, AA, AO, AOA, and GBM on the basis of aggregated data from BTRJ volume 13 (2001-2004). ${ }^{7)}$ Related page numbers in BTRJ volume 13 are shown in brackets [ ].

\section{The Etiology of Gliomas}

All types of gliomas, except for PA, more frequently occur in men than in women [17-20,34], consistent with the data from the US and Republic of Korea. ${ }^{10,11)}$ The mean onset age was 14.8 years for PA, 35.7 years for DA, 40.6 years for OL + OA, 51.9 years for $\mathrm{AA}, 48.5$ years for $\mathrm{AO}+\mathrm{AOA}$, and 62.2 years for GBM, showing an older onset age for higher-grade 
gliomas. The incidence rates of $\mathrm{DA}, \mathrm{OL}+\mathrm{OA}, \mathrm{AA}$, $\mathrm{AO}+\mathrm{AOA}$, and GBM in subjects aged $<20$ years were $15 \%, 5 \%, 7 \%, 2 \%$, and $3 \%$, respectively, whereas those in subjects aged $\geq 70$ years were $5 \%, 3 \%, 14 \%, 5 \%$, and $25 \%$, respectively, showing that oligodendroglial tumors are less common in children and elderly subjects. Fifty-six per cent of GBM cases occurred in elderly patients aged $\geq 60$ years. The incidence of GBM increased with age, with the following incidence rates per 100,000 subjects: < 20 years, $0.14 ; 45-54$ years, 3.66 ; 55-64 years, 8.16; and 65-74 years, 13.21.10)

The main symptoms of gliomas were headache, seizure, and focal symptoms such as hemiparesis. Seizures at onset were more frequent in oligodendroglial tumors, and the incidence rates of DA, $\mathrm{OL}+\mathrm{OA}, \mathrm{AA}, \mathrm{AO}+\mathrm{AOA}$, and GBM were $38 \%$, $60 \%, 28 \%, 31 \%$, and $13 \%$, respectively [37]. The incidence rates of seizures occurring during the entire treatment course for DA, OL + OA, AA, $\mathrm{AO}+\mathrm{AOA}$, and GBM were reported to be $45 \%$, $64 \%, 41 \%, 46 \%$, and $30 \%$, respectively [46]. Anticonvulsants were used for more than half of glioma cases [53]. These data are compatible with $70-90 \%$ of grade II glioma cases ${ }^{12)}$ and $29-49 \%$ of GBM cases ${ }^{13)}$ with seizures at onset. The incidence rates of any focal symptoms at onset of DA, OL + $\mathrm{OA}, \mathrm{AA}, \mathrm{AO}+\mathrm{AOA}$, and GBM were $25 \%, 16 \%$, $44 \%, 34 \%$, and $59 \%$, respectively [37]. GBMs and oligodendroglial tumors were reported to show intratumoral bleeding at onset ${ }^{14)}$ and its incidence was $<2 \%$ (AO + AOA: $2.2 \%$, GBM: $1.1 \%)$.

Asymptomatic gliomas are rare, with incidence rates of only $8 \%$ in $\mathrm{DA}, 10 \%$ in OL $+\mathrm{OA}, 3 \%$ in $\mathrm{AA}, 5 \%$ in $\mathrm{AO}+\mathrm{AOA}$, and $3 \%$ in GBM. The incidence of asymptomatic grade II glioma was reported to range from $3.0 \%$ to $9.6 \%,{ }^{15,16)}$ but such glioma is rarely diagnosed in GBM patients.

The prevalence rates of patients with Karnofsky performance status (KPS) scores $\geq 90$ were $65 \%$, $80 \%, 39 \%, 57 \%$, and $25 \%$ in DA, OL + OA, AA, $\mathrm{AO}+\mathrm{AOA}$, and GBM. The prevalence rates of patients with a KPS $\leq 70$ were $13 \%, 9 \%, 34 \%$, $19 \%$, and $49 \%$, respectively [44]. Among the GBM patients, only a quarter had very mild symptoms and half had severe symptoms at onset.

Among 2,827 glioma cases, 2.7\% were accompanied with other systemic cancers, mostly before they were diagnosed [46]. The incidence of accompanying systemic cancer or other central nervous system tumors was $3.4 \%$ in glioma patients and $0.6 \%$ in GBM patients.

The incidence rates of radiological findings of single and multiple lesions at onset of DA, OL + $\mathrm{OA}, \mathrm{AA}, \mathrm{AO}+\mathrm{AOA}$, and GBM were $95 \%, 99 \%$,
$92 \%, 96 \%$, and $89 \%$, and $5 \%, 1 \%, 7 \%, 4 \%$, and $9 \%$, respectively [39]. The incidence of leptomeningeal metastases (LMMs) at onset was reported to be $<1 \%$ in AA or GBM. GBM was reported to have multiple lesions at onset, with an incidence of $0.5-20 \% .{ }^{17)}$

Gliomas commonly occur in the cerebrum, especially in the frontal lobe at an incidence rate of $41 \%$ in DA, $38 \%$ in $\mathrm{AA}$, and $31 \%$ in GBM [40]. In particular, oligodendroglial tumors are more common in the frontal lobe, with incidence rates of $68 \%$ and $61 \%$ in $\mathrm{OL}+\mathrm{OA}$ and $\mathrm{AO}+\mathrm{AOA}$. The incidence rates of infratentorial lesions in $\mathrm{DA}, \mathrm{OL}+\mathrm{OA}, \mathrm{AA}$, $\mathrm{AO}+\mathrm{AOA}$, and GBM were $15.2 \%, 0.5 \%, 14.0 \%$, $1.7 \%$, and $4.8 \%$, respectively, demonstrating that oligodendroglial tumors in infratentorial lesions are less common.

Regarding hereditary tumors, 37 patients had brain tumors associated with neurofibromatosis type I [47]. The incidence rates of glioma per the total number of cases of each histological type were as follows: PA, 6 patients $(3.1 \%)$; DA, 5 patients $(1.8 \%)$; AA, 3 patients (1.2\%); and GBM, 7 patients $(0.7 \%)$.

\section{Prognosis of Glioma Patients}

\section{Overall survival}

Table 1 shows the patients' median OS and PFS [55] according to glioma type. The median OSs of the DA, AA, and GBM patients were not reached (NR), 38.0 months, and 15.0 months, respectively, and the median PFSs were 84.1, 19.0, and 8.1 months, respectively. Among the DA cases, the gemistocytic astrocytoma subtype had a shorter median OS and a PFS $\leq 76.1$ and 36.0 months, respectively. One of the reason is that gemistocytic astrocytomas presented at a significantly older age than other variants and the median age of diffuse $(n=269)$, fibrillary $(n=71)$, protoplasmic $(n=29)$, and gemistocytic astrocytoma $(\mathrm{n}=13)$ were 38.2 , $33.3,34.0$, and 46.2 years. Similar age distribution was reported by Surveillance, Epidemiology, and End Results Program (SEER) database and median age of fibrillary and gemistocytic variants were 37.7 years and 46.8 years, respectively. ${ }^{18)}$ The KaplanMeier survival curves of OS and PFS between OL and $\mathrm{OA}$, or between $\mathrm{AO}$ and $\mathrm{AOA}$ were similar, and the 5-year OS rates of OL, OA, AO, and AOA were $90.6 \%, 89.3 \%, 67.8$, and $68.7 \%$, respectively. The 5 -year PFS rates of DA, OL + OA, AA, AO + AOA, and GBM were $57.0 \%, 74.6 \%, 28.7 \%, 54.0 \%$, and $9.2 \%$, and the 5 -year OS rates were $75.0 \%, 90.0 \%$, $41.1 \%, 68.2 \%$, and $10.1 \%$, respectively. Table 1 also shows the 5-year OS from the nationwide cancer registries of the US (1995-2009) ${ }^{10)}$ and Republic of Korea (1999-2004). ${ }^{19)}$ 
Table 1 Overall survival and progression free survival (months)

\begin{tabular}{|c|c|c|c|c|c|c|c|c|c|}
\hline \multirow[b]{2}{*}{ Histology } & \multirow{2}{*}{$\begin{array}{c}\text { Registered } \\
\text { number }\end{array}$} & \multirow[b]{2}{*}{ Rate } & \multirow{2}{*}{$\begin{array}{l}\text { Estimated } \\
\text { number }\end{array}$} & \multicolumn{2}{|c|}{ PFS } & \multicolumn{2}{|c|}{ OS } & \multirow{2}{*}{\multicolumn{2}{|c|}{$\frac{\text { USA Korea }}{5-y \text { OS (\%) }}$}} \\
\hline & & & & med & $\begin{array}{c}5-\mathrm{y} \\
\text { PFS }(\%)\end{array}$ & med & $\begin{array}{c}5-y \\
\text { OS }(\%)\end{array}$ & & \\
\hline Pilocytic astrocytoma & 193 & $1.4 \%$ & 287 & NR & 73.8 & NR & 92.1 & 94.1 & \\
\hline Ganglioglioma & 60 & $0.4 \%$ & 89 & NR & 78.9 & NR & 98.1 & & \\
\hline Diffuse astrocytoma & 382 & $2.8 \%$ & 569 & 84.1 & 57.0 & NR & 75.0 & 47.1 & 51.6 \\
\hline Gemistocytic astrocytoma & 29 & $0.2 \%$ & 43 & 36.0 & 31.6 & 76.1 & 70.4 & & \\
\hline Oligodendroglial tumor & 211 & $1.6 \%$ & 314 & NR & 74.6 & NR & 90.0 & & \\
\hline Oligodendroglioma & 121 & $0.9 \%$ & 180 & 109.1 & 76.5 & NR & 90.6 & 79.1 & 73.5 \\
\hline Oligoastrocytoma & 90 & $0.7 \%$ & 134 & NR & 72.2 & NR & 89.3 & & \\
\hline Anaplastic astrocytoma & 513 & $3.8 \%$ & 764 & 19.0 & 28.7 & 38.0 & 41.1 & 25.9 & 25.2 \\
\hline $\begin{array}{l}\text { Anaplastic oligodendroglial } \\
\text { tumor }\end{array}$ & 232 & $1.7 \%$ & 345 & 71.0 & 54.0 & NR & 68.2 & & \\
\hline $\begin{array}{l}\text { Anaplastic } \\
\text { oligodendroglioma }\end{array}$ & 126 & $0.9 \%$ & 188 & 52.0 & 49.9 & 102.1 & 67.8 & 49.4 & 50.4 \\
\hline $\begin{array}{l}\text { Anaplastic } \\
\text { oligoastrocytoma }\end{array}$ & 106 & $0.8 \%$ & 158 & 80.1 & 58.6 & NR & 68.7 & & \\
\hline Glioblastoma & 1,489 & $11.1 \%$ & 2,217 & 8.1 & 9.2 & 15.0 & 10.1 & 4.7 & 8.9 \\
\hline Gliomatosis cerebri & 47 & $0.3 \%$ & 70 & 12.0 & 25.9 & 17.0 & 21.2 & & \\
\hline Ependymoma & 72 & $0.5 \%$ & 107 & 117.0 & 73.1 & NR & 88.5 & 82.5 & 81.5 \\
\hline Anaplastic ependymoma & 55 & $0.4 \%$ & 82 & 22 & 35.1 & NR & 58.1 & & 53.2 \\
\hline Central neurocytoma & 65 & $0.5 \%$ & 97 & NR & 79.0 & NR & 98.4 & & \\
\hline
\end{tabular}

BTRJ 2001-2004, United States of America (USA) 1995-2009, Korea 1999-2004. BTRJ: Brain Tumor Registry of Japan, med: median, NR: not reached, OS: overall survival, PFS: progression free survival.

BTRJ is a hospital-based registry that compares population-based data from the US and Republic of Korea. The 5-year OS rates were much higher in Japan than in those countries. Figure 1 shows the 5-year OS from 1969 to 2004 reported in each BTRJ. ${ }^{1-7,20)}$ Most of the patients with gliomas had improved prognoses; however, the prognoses of the patients with GBM were still poor. This was reported in the era before temozolomide (TMZ: Merck; Kenilworth, New Jersey, USA). The median OS of patients with GBM in the US and Republic of Korea was reported to be improved after the introduction of TMZ or bevacizumab. ${ }^{19,21)}$ Prognosis of patients with GBM is expected to be shown in next volume of BTRJ.

Table 2 shows the median OS in each glioma subtype group according to the KPS score at onset. With the exception of the patients in the AO + AOA group, those with a KPS score $\geq 90$ showed a significantly prolonged OS compared with those with a KPS $\leq 80$ (log rank, $\mathrm{p}<0.001)$. For the patients with DA, $\mathrm{OL}+\mathrm{OA}, \mathrm{AA}, \mathrm{AO}+\mathrm{AOA}$, and GBM, and a KPS score $\geq 90$ with virtually no neurological symptoms, the 5 -year OS rates were $85.4 \%, 92.4 \%, 55.0 \%$, $68.2 \%$, and $19.9 \%$, respectively. As the pattern of recurrence was previously reported, most patients with $\mathrm{DA}, \mathrm{OL}+\mathrm{OA}, \mathrm{AA}, \mathrm{AO}+\mathrm{AOA}$, and GBM developed local recurrence at incidence rates of

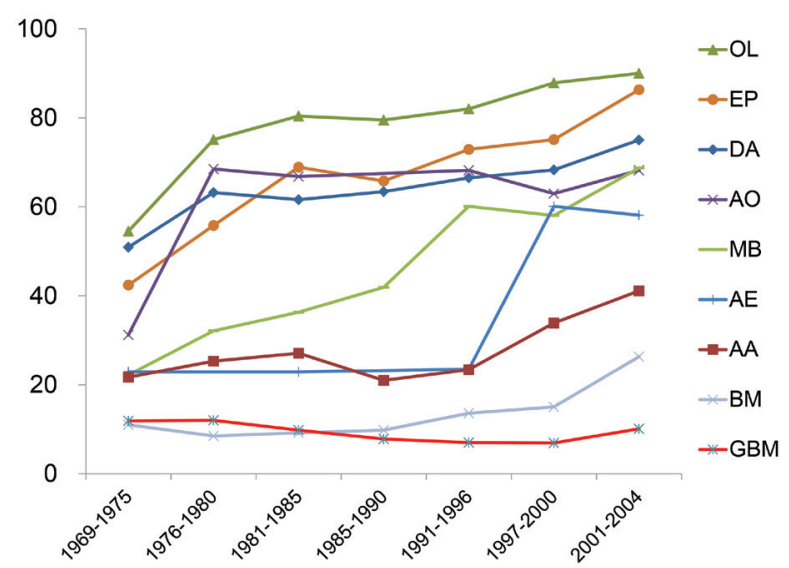

Fig. 1 The 5-year overall survival rate of malignant brain tumors from 1969 to 2004 reported in each BTRJ. AA: anaplastic astrocytoma, AE: anaplastic ependymoma, AO: anaplastic oligodendroglioma, BM: brain metastases, BTRJ: Brain Tumor Registry of Japan, DA: diffuse astrocytoma, EP: ependymoma, GBM: glioblastoma, MB: medulloblastoma, OL: oligodendroglioma.

89\%, 94\%, 89\%, 87\%, and 88\% [57]. Approximately $80 \%$ of GBM were reported to recur within $2 \mathrm{~cm}$ of the initial tumor bed. ${ }^{22,23)}$

\section{Extent of resection (EOR)}

The EOR in this report was based mainly on 
Table 2 Overall survival and 5-year OS depending on a Karnofsky performance status score at onset

\begin{tabular}{|c|c|c|c|c|c|c|c|c|c|c|c|c|c|c|c|}
\hline \multirow{2}{*}{ KPS } & \multicolumn{3}{|c|}{$\mathrm{DA}(\mathrm{n}=351)$} & \multicolumn{3}{|c|}{$\mathrm{OL}+\mathrm{OA}(\mathrm{n}=205)$} & \multicolumn{3}{|c|}{ AA $(n=487)$} & \multicolumn{3}{|c|}{$\mathrm{AO}+\mathrm{AOA}(\mathrm{n}=227)$} & \multicolumn{3}{|c|}{ GBM (n = 1,381) } \\
\hline & $\mathrm{n}$ & OS & $5 \mathrm{y}-\mathrm{OS}$ & $\mathrm{n}$ & OS & $5 \mathrm{y}$-OS & $\mathrm{n}$ & OS & $5 \mathrm{y}-\mathrm{OS}$ & $\mathrm{n}$ & OS & $5 y-O S$ & $\mathrm{n}$ & OS & $5 \mathrm{y}-\mathrm{OS}$ \\
\hline $10-60$ & 36 & 19.0 & $30.3 \%$ & 10 & NR & $70.0 \%$ & 99 & 17.0 & $22.8 \%$ & 31 & 102.1 & $62.4 \%$ & 506 & 12.0 & $5.6 \%$ \\
\hline 70 & 14 & 86.1 & $63.6 \%$ & 8 & 76 & $68.6 \%$ & 72 & 24 & $25.1 \%$ & 14 & 82.1 & $72.7 \%$ & 224 & 13.1 & $5.1 \%$ \\
\hline 80 & 51 & NR & $51.7 \%$ & 18 & NR & $72.2 \%$ & 114 & 31 & & 39 & 110.1 & & 279 & 15 & $5.1 \%$ \\
\hline 90 & 100 & NR & & 59 & NR & & 120 & 53 & & 59 & NR & & 266 & 20 & $19.3 \%$ \\
\hline 100 & 150 & NR & $90.2 \%$ & 110 & NR & $92.6 \%$ & 82 & NR & $61.6 \%$ & 84 & NR & $69.1 \%$ & 106 & 17 & $20.9 \%$ \\
\hline 90-100 & 250 & NR & $85.4 \%$ & 169 & NR & $92.4 \%$ & 202 & 69 & $55.0 \%$ & 133 & NR & $68.2 \%$ & 372 & 19 & $19.9 \%$ \\
\hline
\end{tabular}

AA: anaplastic astrocytoma, AO: oligodendroglioma, AOA: anaplastic oligoastrocytoma, DA: diffuse astrocytoma, GBM: glioblastoma, KPS: Karnofsky performance status, NR: not reached, OA: oligoastrocytoma, OL: oligodendroglioma, OS: overall survival.

the surgeon's description in the patient's clinical record. Gross total resection (GTR), which means complete resection, was performed in $15 \%, 36 \%$, $12 \%, 31 \%$, and $18 \%$ of the DA, OL + OA, AA, AO + AOA, and GBM cases, respectively. An EOR $\geq 95 \%$ and GTR were achieved in $29 \%, 56 \%, 25 \%, 47 \%$, and $34 \%$ of those cases, respectively. One of the reasons that oligodendroglial tumors have a higher EOR than astrocytic tumors is that those tumors locate mainly in frontal lobe. Smith et al. reported that $35 \%$ of 216 grade II glioma cases had GTR, of which $47 \%$ had an EOR $\geq 90 \% .{ }^{24)}$ Sanai et al. also reported that $63 \%$ of $500 \mathrm{GBM}$ cases had an EOR $\geq 95 \% .{ }^{25)}$ Increasing of EORs of gliomas should be needed from these data.

With an EOR of 1-50\% (including biopsy), $50-75 \%$, $75-95 \%, 95-99 \%$, or GTR, the 5-year OS rates were respectively $63.8 \%, 54.5 \%, 80.8 \%, 97.5 \%$, and $95.7 \%$ in DA; $50.0 \%, 47.3 \%, 67.4 \%, 88.1 \%$, and $86.9 \%$ in OL and OA; and $26.4 \%, 50.4 \%, 49.8 \%$, $48.1 \%$, and $62.1 \%$ in $\mathrm{AA} ; 33.4 \%, 45.9 \%, 41.1 \%$, $68.1 \%$, and $68.1 \%$ in $\mathrm{AO}+\mathrm{AOA}$; and $5.8 \%, 6.7 \%$, $3.7 \%, 12.6 \%$, and $15.1 \%$ in GBM. In the GBM cases with an EOR of $1-50 \%$ (including biopsy), $50-75 \%$, $75-95 \%, 95-99 \%$, or GTR, the median OSs were 12.0 months, 15.0 months, 14.0 months, 18.0 months, and 19.0 months, respectively.

No difference in OS was found between the DA or OL + OA cases with an EOR of $1-50 \%$ and those with an EOR of $50-75 \%$. Meanwhile, the OS was significantly prolonged in the cases with an EOR $\geq 75 \%$ compared with those with an EOR of $1-75 \%$ (log rank, $\mathrm{p}=0.04$ in DA and $\mathrm{p}=0.0006$ in OL + OA). For grade III/IV glioma cases, the OS was significantly prolonged in those with an EOR $\geq 50 \%$ compared with those with an EOR of $1-50 \%$ (log rank $\mathrm{p}=0.02$ in $\mathrm{AA}, \mathrm{p}=0.01$ in $\mathrm{AO}+\mathrm{AOA}$, and $\mathrm{p}=0.005$ in GBM).

In the volumetric analysis of EOR, OS was significantly improved with EOR $\geq 80 \%$ for grade II gliomas $^{24)}$ and EOR $\geq 78 \%$ for GBMs. ${ }^{25)}$

\section{Initial therapy}

More than $95 \%$ of the patients with gliomas underwent biopsy or tumor resection [49]. Initial radiotherapy (RT) [62] was performed in $56 \%, 52 \%$, $89 \%, 79 \%$, and $87 \%$ of the patients with DA, OL + $\mathrm{OA}, \mathrm{AA}, \mathrm{AO}+\mathrm{AOA}$, and GBM, respectively [50]. Re-RT was performed in $10-15 \%$ of the patients in each subtype group [51]. Chemotherapy was performed in $78 \%, 82 \%$, and $69 \%$ of the patients in the AA, $\mathrm{AO}+\mathrm{AOA}$, and GBM groups, respectively [48]. TMZ was approved in 2006 in Japan and therefore, the most frequently used chemotherapeutic agents are nimustine chloride (ACNU), platinum-containing drugs, vincristine, and interferon. More than $80 \%$ of the patients who underwent chemotherapy received an ACNU-based regimen [52]. Because ACNU induces bone marrow suppression especially in elderly patients, ACNU is not generally used for patients aged $\geq 70$ years. Steroids were used in $27 \%, 27 \%, 45 \%, 37 \%$, and $53 \%$ of the patients in the $\mathrm{DA}, \mathrm{OL}+\mathrm{OA}, \mathrm{AA}, \mathrm{AO}+\mathrm{AOA}$, and $\mathrm{GBM}$ groups, respectively.

For the OS of patients in the DA group, depending on initial treatment, the 5-year OS of the subjects who underwent surgery alone (operation [OP]), $\mathrm{OP}+\mathrm{RT}$, and OP + chemoradiotherapy (CRT) were $85.6 \%(\mathrm{n}=142), 68.8 \%(\mathrm{n}=91)$, and $66.9 \%(\mathrm{n}=$ 111), respectively, indicating that the OS of the patients who received early RT with or without chemotherapy was significantly worse than the OS of the patients who underwent observation alone after OP (log rank $\mathrm{p}=0.002$ ) (Fig. 2A). The median ages of the patients in the OP-only and OP + RT groups were 33.8 years and 38.9 years, respectively; the proportions of patients aged $\geq 40$ years were $36 \%$ and $48 \%$, respectively; and the proportions 

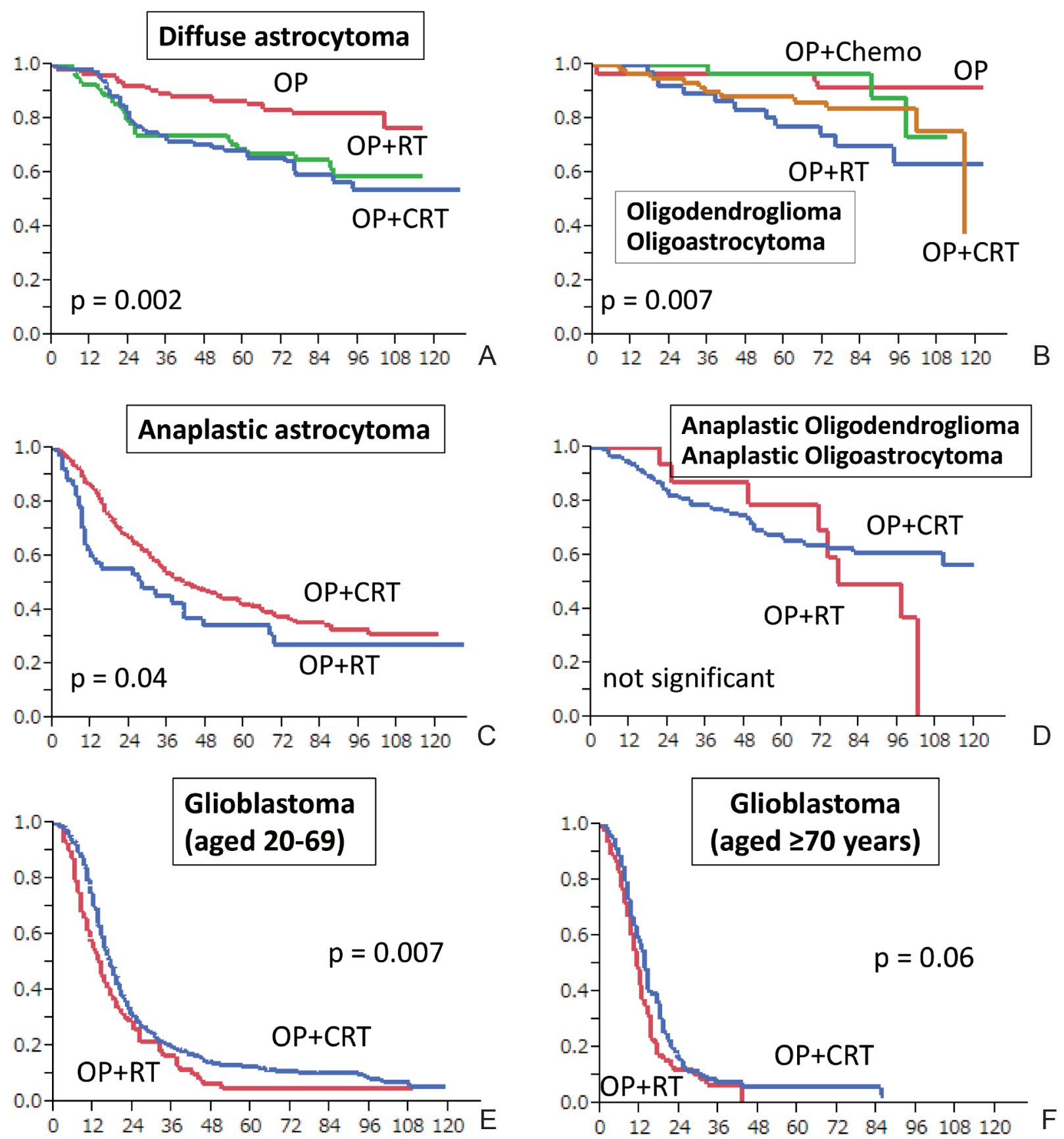

Fig. 2 Overall survival of grades II-IV gliomas. A: diffuse astrocytoma, B: oligodendroglioma + oligoastrocytoma, C: anaplastic astrocytoma, D: anaplastic oligodendroglioma + anaplastic oligoastrocytoma, E: glioblastoma patients aged 20-69 years, F: glioblastoma patients aged $\geq 70$ years. Chemo: chemotherapy, CRT: chemoradiotherapy, OP: surgery, RT: radiotherapy.

of those with an EOR $\geq 75 \%$ were $61 \%$ and $36 \%$, respectively. This shows that the OP-alone group included younger patients and patients with a greater extent of resection. A multivariate analysis of 258 patients aged $\geq 20$ years who had supratentorial DA was conducted according to age, KPS score, resection extent, and whether they underwent early RT. The hazard ratio (HR), 95\% confidence interval (CI), and $\mathrm{p}$ values were as follows; in the subjects aged $\geq 40$ years, HR: 1.88 (95\% CI, 1.09-3.32; p = 0.02); in the patients with a KPS score $\leq 80$, HR: $2.89(95 \%$ CI, 1.60-5.10; $\mathrm{p}=0.0006$ ); and in the patients with an EOR $\leq 75 \%$, HR: 2.77 (95\% CI, 1.54-5.18; p = 0.0006). This means that although age $\geq 40$ years, KPS score, and resection extent were significant prognostic factors, undergoing early RT had a HR 
of 0.93 (95\% CI, 0.51-1.66; p = 0.81).

Similarly, in the OL + OA group, the 5-year OS rates of the subjects who underwent OP alone, $\mathrm{OP}+$ chemotherapy, OP + RT, and OP + CRT were $96.6 \%(\mathrm{n}=60), 96.7 \%(\mathrm{n}=40), 77.3 \%(\mathrm{n}=43)$, and $86.2 \%(\mathrm{n}=116)$, respectively, indicating that the OS of the patients who underwent early RT was significantly worse than the OS of the patients who underwent observation alone or chemotherapy after OP (log rank $\mathrm{p}=0.007$ ) (Fig. 2B). A multivariate analysis of 193 patients aged $\geq 20$ years who had supratentorial OL + OA revealed the following HR, 95\% CI, and $\mathrm{p}$ values: in the subjects aged $\geq 40$ years, 2.88, 1.19-8.04, and $\mathrm{p}=0.02$; in the patients with a KPS $\leq 80,1.73,0.68-4.04$, and $\mathrm{p}=0.24$; and in patients with an EOR $\leq 75 \%, 5.39,2.36-12.6$, $\mathrm{p}<0.0001$. While age and EOR were significant prognostic factors, undergoing early RT was associated with worse prognosis in the OL + OA group, with an HR of 2.86 (95\% CI, 1.19-7.97; $\mathrm{p}=0.02$ ). Only $14 \%$ of the 193 patients died, indicating a low event rate, which might have influenced the results. OS was reported to not significantly differ between early RT and non-early RT for patients with grade II gliomas. ${ }^{26)}$ Patients with grade II glioma survived longer. However, in order to obtain conclusive findings regarding the effect of early RT, studies with longer follow-up periods are necessary.

In the AA group, the median OSs of the subjects who underwent OP alone, OP + RT, and OP + CRT were 14.0 months $(\mathrm{n}=42), 28.0$ months $(\mathrm{n}=67)$, and 41.0 months $(n=381)$, respectively, indicating that the OS of the patients with OP + CRT was significantly longer than the OS of the patients with $\mathrm{OP}+\mathrm{RT}(\log$ rank $\mathrm{p}=0.04)$ (Fig. 2C).

In the AO + AOA group, the OSs of the subjects who underwent OP alone, OP + RT, and OP + CRT were 64.1 months $(\mathrm{n}=21), 77.1$ months $(\mathrm{n}=$ $18)$, and NR ( $=163)$, respectively (Fig. 2D). The number of patients who underwent $\mathrm{OP}$ alone or $\mathrm{OP}+\mathrm{RT}$ was small, without any significant difference between the groups.

In the GBM group, the OSs of the subjects who underwent OP alone, OP + RT, and OP + CRT were 6.1 months $(n=144), 12.0$ months $(n=272)$, and 17.0 months ( $\mathrm{n}=991)$, respectively, demonstrating that OP + CRT, mainly with ACNU, significantly improved OS (log rank $\mathrm{p}<0.0001)$. The frequency rates of OP alone, OP + RT, and OP + CRT in the patients aged 20-69 years were $7.5 \%, 11.7 \%$, and $76.6 \%$, respectively, and the median OSs of the patients were 7.1 months $(\mathrm{n}=80), 14.0$ months $(\mathrm{n}=125)$, and 17.0 months $(\mathrm{n}=815)$, respectively. OP + CRT significantly improved OS compared with OP + RT (log rank p = 0.007) (Fig. 2E). ACNU-based regimens were used in
$80.4 \%$ of the patients, and platinum-based regimens were used in $14.4 \%$ of the patients. The median OSs of the patients aged $\geq 70$ years who underwent OP alone, OP + RT, and OP + CRT were 6.0 months (n =63), 11.0 months $(\mathrm{n}=138)$, and 13.0 months $(\mathrm{n}=$ 140), respectively. OP + RT significantly improved OS compared with OP alone (log rank $p<0.001$ ), but no significant difference was observed between $\mathrm{OP}+\mathrm{RT}$ and $\mathrm{OP}+\mathrm{CRT}(\log$ rank $\mathrm{p}=0.06)$ (Fig. 2F).

For the patients aged 20-69 years who had supratentorial GBM with a KPS $\geq 70$ ( $\mathrm{n}=510$ ), the median OS and PFS were 18.0 months and 8.1 months, respectively. These data are similar to those reported in previous clinical studies. The median OS and PFS of the patients who underwent $\mathrm{RT}+\mathrm{ACNU}$ were 19.0 months and 6.2 months, respectively, in the phase II study of the Japan Clinical Oncology Group (JCOG) 0305, ${ }^{27}$ ) and those of the patients who underwent RT + TMZ were 14.6 months and 6.9 months, respectively, in the phase III study of RT alone versus RT + TMZ. ${ }^{28)}$

The median OS of the patients diagnosed with GBM between 2007 and 2009 in the US was reported be about only 7-9 months, but that of the patients who underwent RT + TMZ was 14 months. ${ }^{21)}$ Sixty-seven and $18 \%$ of patients with GBM underwent OP + CRT and OP + RT, respectively, which shows that most of the patients in Japan received aggressive therapies. However, $72.8 \%$ of the patients underwent $\mathrm{OP}+\mathrm{RT}$, but only $47 \%$ of the patients underwent $\mathrm{OP}+\mathrm{RT}+\mathrm{TMZ}$ in the US in 2008. Chang et al. also reported that only $54 \%$ of patients with grade III/IV gliomas underwent CRT between 1997 and 2000. ${ }^{12)}$ Considering that most of the patients in Japan received aggressive therapies, including RT + CRT, the OS of Japanese patients might be superior to that of the US patients.

\section{Adult and juvenile gliomas}

According to the patients' ages, the 5-year OS rates of the subjects aged $<20$ years, 20-39 years, 40-59 years, and $\geq 60$ years were respectively $60.0 \%, 83.2 \%, 79.6 \%$, and $38.2 \%$ in DA, and $18.0 \%, 65.0 \%, 53.0 \%$, and $24.0 \%$ in AA, indicating that the subjects aged $<20$ years and those aged $\geq 60$ years who had both DA and AA had poorer prognoses than those aged 20-59 years (log rank $\mathrm{p}<0.05$ in DA and $\mathrm{p}<0.0001$ in AA) [65]. For GBM, the median OSs of the subjects aged $<20$ years, 20-59 years, and $\geq 60$ years were 17.0, 18.0, and 13.0 months, respectively, and their 5 -year OS rates were $7.8 \%, 16.4 \%$, and $4.0 \%$, respectively. No significant difference was observed between the juvenile patients and the adult patients aged $<60$ years in patients with GBM. 
The patients aged $<20$ years rarely $(\mathrm{n}=11$ ) had $\mathrm{OL}+\mathrm{OA}$, and all the patients survived for $>5$ years. The 5-year OS rates of the subjects aged 20-39 years, 40-59 years, and $\geq 60$ years were respectively $97.3 \%, 88.1 \%$, and $55.4 \%$ in OL + OA, and $74.0 \%$, $66.9 \%$, and $60.9 \%$ in AO + AOA. Patients aged $\geq 40$ years who had OA + OL (log rank $\mathrm{p}<0.001)$ and those aged $\geq 50$ years who had AO + AOA (log rank $\mathrm{p}<0.03$ ) had significantly poorer prognoses.

\section{Supratentorial and infratentorial lesions}

The incidence rates of infratentorial DA, AA, and GBM were $14 \%, 13 \%$, and $4 \%$, respectively [66]. Infratentorial oligodendroglial tumor is rare. Infratentorial OL + OA cases have not been reported in this report, and the incidence of infratentorial $\mathrm{AO}+\mathrm{AOA}$ was only $2 \%$.

The patients with infratentorial DA and AA had significantly poorer prognoses, and the 5-year OS rates of the patients with supratentorial and infratentorial lesions were $79.5 \%$ and $46.2 \%$ in DA, and $42.4 \%$ and $31.4 \%$ in AA, respectively.

Supratentorial and infratentorial GBM had no significant differences, and their median OS rates were 15.0 months and 14.0 months, respectively. For the GBM patients aged 20-69 years, with a KPS $\geq 70$, no significant difference in median OS was observed between the frontal lobe (18.0 months, $\mathrm{n}=$ 207), temporal lobe (16.1 months, $n=199)$, parietal lobe (20.1 months, $\mathrm{n}=87$ ), and occipital lobe (18.1 months, $n=37$ ). However, the median OS of the patients with cerebellar GBM was 27 months ( $\mathrm{n}=$ 22 ), indicating a better prognosis as previously. ${ }^{29)}$

\section{Brainstem gliomas}

The reported number of patients with brainstem gliomas was 186 [75], of whom 66\% ( $=123)$ had histological diagnoses (AA: 20.4\%, DA: 19.9\%, GBM: $10.2 \%$, and PA: $8.6 \%$ ). The median OS rates of the patients aged $<20$ years and 20-59 years were 18.1 months $(\mathrm{n}=16)$ and NR $(\mathrm{n}=20)$ in DA (log rank $\mathrm{p}=0.007), 15.0$ months $(\mathrm{n}=14)$ and 31.0 months ( $\mathrm{n}=17)$ in AA (log rank $\mathrm{p}=0.11), 14.0$ months $(\mathrm{n}=7)$ and 9.0 months $(\mathrm{n}=9)$ in GBM (log rank $\mathrm{p}=0.2)$, and 9.0 months $(\mathrm{n}=38)$ and 92.1 months ( $\mathrm{n}=17$ ) in histologically unknown gliomas (log rank $\mathrm{p}=0.007)$. Patients aged $<20$ years who had both DA and unknown gliomas had poorer prognosis. Adult patients with brainstem gliomas had better prognoses than children, ${ }^{30)}$ consistent with our report.

\section{Complications}

The incidence of complications that occur during the treatment course for each glioma type was reported to be $11 \%, 11 \%, 20 \%, 19 \%$ and $21 \%$ in DA,
$\mathrm{OL}+\mathrm{OA}, \mathrm{AA}, \mathrm{AO}+\mathrm{AOA}$, and GBM, respectively [70]. Major complications include pneumonia, with incidence rates of $3-10 \%$. The respective incidence of intracranial hemorrhage and cerebral infarction is $<3 \%$. Deep venous thrombosis and pulmonary embolism are life-threatening complications that are often observed in approximately $10 \%$ of highergrade gliomas, ${ }^{31)}$ and their incidence in BTRJ is $<3 \%$ (GBM: $2.3 \%$ ).

\section{Causes of death}

Most of the patients died of neurological causes including $\mathrm{LMM}$, accounting for $84 \%, 72 \%, 86 \%$, $75 \%$, and $83 \%$ of DA, OL + OA, AA, AO + AOA, and GBM cases. Meanwhile, the mortality rates by LMM were $3 \%, 3 \%, 6 \%, 4 \%$, and $4 \%$, respectively [67]. Pneumonia-related mortality rates with neurological deterioration were $39 \%, 52 \%, 49 \%, 50 \%$, and $48 \%$, respectively.

Treatment-related death is not so rare, accounting for $3-6 \%$ of deaths. Among the patients with DA, $\mathrm{OL}+\mathrm{OA}, \mathrm{AA}, \mathrm{AO}+\mathrm{AOA}$, and GBM, the incidence rates of death caused by accidents and other diseases were $0 \%, 7 \%, 1 \%, 4 \%$, and $2 \%$, respectively. The autopsy rate was $5.2 \%(71 / 1358)$.

The percentages of patients with $\mathrm{DA}, \mathrm{OL}+\mathrm{OA}$, $\mathrm{AA}, \mathrm{AO}+\mathrm{AOA}$, and GBM who were treated in a single hospital without transferring to another hospital were $71 \%, 77 \%, 59 \%, 68 \%$, and $50 \%$, respectively [69]. The number of patients who were transferred to hospices and other institutions for palliative care was small, their proportions being $10 \%, 4 \%, 17 \%$, $11 \%$, and $26 \%$, respectively. For place of death, the proportions of those who died in hospitals with a neurosurgical unit were $71 \%, 76 \%, 78 \%, 64 \%$, and $70 \%$, respectively; those who died in hospitals, hospices, and nursing care institutions without a neurosurgical unit were $13 \%, 7 \%, 11 \%, 18 \%$, and $15 \%$, respectively; and those who died at home were $3 \%, 7 \%, 2 \%, 1 \%$, and $3 \%$, respectively. Of cancer patients, $12-45 \%$ die at home in Europe, ${ }^{32)}$ while only $8 \%$ die at home in Japan. Furthermore, patients with gliomas rarely die at home in Japan. One of the reasons that the OS of glioma patients in Japan is superior to that in other countries is that more than half of Japanese patients continue to undergo aggressive therapies in the same hospital and die in the neurosurgical care unit.

\section{Conclusion}

BTRJ had been edited for all the patients, researchers, and especially for clinicians at bedside to give useful information about brain tumors and to contribute to the advances in brain tumor treatment. This report 
was based on cumulative retrospective data in Japan, so the data analysis had various limitations and its interpretation requires caution. However, analysis of the data registered by a number of neurosurgeons has revealed various problematic issues pertaining to the diagnosis and treatment of brain tumors.

From this report, the causes of poor prognosis of GBM include: most patients are elderly; most patients have a poor KPS score; the asymptomatic onset of GBM is rare and cannot be diagnosed during a systematic health screening; cases of GTR of the tumor are rare; complications such as pneumonia are common; and medical treatments, especially available drugs, are limited.

Based on this report, we hope that various research and clinical trials will be carried out, evidence pertaining to the treatment of brain tumors will be established, and the therapeutic outcomes of all patients with malignant brain tumors will improve.

\section{Acknowledgments}

This project was conducted by the JNS. The authors express their great appreciation to the all members of the JNS and medical staff at the registered hospitals in Japan. They also thank Mr. Asanao Shimokawa and Dr. Etsuo Miyaoka from the Department of Mathematics, Tokyo University of Science, Shinjuku, Tokyo, for their contributions in the statistical analysis.

\section{Conflicts of Interest Disclosure}

The authors declare no conflict of interest (COI). All authors have registered online Self-reported COI Disclosure Statement Forms through the website for JNS members.

\section{References}

1) Committee of Brain Tumor Registry of Japan: Report of Brain Tumor Registry of Japan 1969 and 1974 vol. 1. 1-45, 1977

2) Brain Tumor Registry of Japan. Neurol Med Chir (Tokyo) 32: (7 Spec No): 381-547, 1992

3) Special Report of Brain Tumor Registry of Japan (1969-1990), Vol. 9. Neurol Med Chir (Tokyo) 39: 59-107, 1999

4) Report of Brain Tumor Registry of Japan (1969-1993), Vol. 10. Neurol Med Chir (Tokyo) 40(Suppl): 1-106, 2000

5) Committee of Brain Tumor Registry of Japan: Report of Brain Tumor Registry of Japan (1969-1996), Vol. 11. Neurol Med Chir (Tokyo) 43(Suppl): i-vii, 1-111, 2003

6) Report of Brain Tumor Registry of Japan (1984-2000),
Vol. 12. Neurol Med Chir (Tokyo) 49(Suppl): PS1PS96, 2009

7) Committee of Brain Tumor Registry of Japan: Report of Brain Tumor Registry of Japan (2001-2004), Vol. 13. Neurol Med Chir (Tokyo) 54: 1-102, 2014

8) Louis DN, Ohgaki H, Wiestler OD, Cavenee WK, Burger PC, Jouvet A, Scheithauer BW, Kleihues P: WHO Classification of Tumours of the Central Nervous System, ed 4. Lyon, IARC Press, 2007

9) Nakamura H, Makino K, Yano S, Kuratsu J; Kumamoto Brain Tumor Research Group: Epidemiological study of primary intracranial tumors: a regional survey in Kumamoto prefecture in southern Japan-20-year study. Int J Clin Oncol 16: 314-321, 2011

10) Dolecek TA, Propp JM, Stroup NE, Kruchko C: CBTRUS statistical report: primary brain and central nervous system tumors diagnosed in the United States in 2005-2009. Neuro Oncol 14(Suppl 5): v1-v49, 2012

11) Lee CH, Jung KW, Yoo H, Park S, Lee SH: Epidemiology of primary brain and central nervous system tumors in Korea. J Korean Neurosurg Soc 48: 145-152, 2010

12) Chang EF, Potts MB, Keles GE, Lamborn KR, Chang SM, Barbaro NM, Berger MS: Seizure characteristics and control following resection in 332 patients with low-grade gliomas. J Neurosurg 108: 227-235, 2008

13) van Breemen MS, Wilms EB, Vecht CJ: Epilepsy in patients with brain tumours: epidemiology, mechanisms, and management. Lancet Neurol 6: 421-430, 2007

14) Velander AJ, DeAngelis LM, Navi BB: Intracranial hemorrhage in patients with cancer. Curr Atheroscler Rep 14: 373-381, 2012

15) Potts MB, Smith JS, Molinaro AM, Berger MS: Natural history and surgical management of incidentally discovered low-grade gliomas. J Neurosurg 116: 365-372, 2012

16) Bauchet L, Rigau V, Mathieu-Daudé H, FigarellaBranger D, Hugues D, Palusseau L, Bauchet F, Fabbro M, Campello C, Capelle L, Durand A, Trétarre B, Frappaz D, Henin D, Menei P, Honnorat J, Segnarbieux F: French brain tumor data bank: methodology and first results on 10,000 cases. $J$ Neurooncol 84: 189-199, 2007

17) Thomas RP, Xu LW, Lober RM, Li G, Nagpal S: The incidence and significance of multiple lesions in glioblastoma. J Neurooncol 112: 91-97, 2013

18) Babu R, Bagley JH, Park JG, Friedman AH, Adamson C: Low-grade astrocytomas: the prognostic value of fibrillary, gemistocytic, and protoplasmic tumor histology. J Neurosurg 119: 434-441, 2013

19) Jung KW, Ha J, Lee SH, Won YJ, Yoo H: An updated nationwide epidemiology of primary brain tumors in republic of Korea. Brain Tumor Res Treat 1: 16-23, 2013

20) A statistical study of brain tumors in Japan: general features. The Committee of the Brain Tumor Registry in Japan. Jpn J Clin Oncol 17: 19-28, 1987 
21) Johnson DR, Leeper HE, Uhm JH: Glioblastoma survival in the United States improved after Food and Drug Administration approval of bevacizumab: a population-based analysis. Cancer 119: 3489-3495, 2013

22) Brandes AA, Tosoni A, Franceschi E, Sotti G, Frezza G, Amistà P, Morandi L, Spagnolli F, Ermani M: Recurrence pattern after temozolomide concomitant with and adjuvant to radiotherapy in newly diagnosed patients with glioblastoma: correlation With MGMT promoter methylation status. J Clin Oncol 27: 1275-1279, 2009

23) Gebhardt BJ, Dobelbower MC, Ennis WH, Bag AK, Markert JM, Fiveash JB: Patterns of failure for glioblastoma multiforme following limited-margin radiation and concurrent temozolomide. Radiat Oncol 9: 130, 2014

24) Smith JS, Chang EF, Lamborn KR, Chang SM, Prados MD, Cha S, Tihan T, Vandenberg S, McDermott MW, Berger MS: Role of extent of resection in the longterm outcome of low-grade hemispheric gliomas. $J$ Clin Oncol 26: 1338-1345, 2008

25) Sanai N, Polley MY, McDermott MW, Parsa AT, Berger MS: An extent of resection threshold for newly diagnosed glioblastomas. J Neurosurg 115: 3-8, 2011

26) van den Bent MJ, Afra D, de Witte O, Ben Hassel M, Schraub S, Hoang-Xuan K, Malmström PO, Collette L, Piérart M, Mirimanoff R, Karim AB; EORTC Radiotherapy and Brain Tumor Groups and the UK Medical Research Council: Long-term efficacy of early versus delayed radiotherapy for low-grade astrocytoma and oligodendroglioma in adults: the EORTC 22845 randomised trial. Lancet 366: 985-990, 2005

27) Shibui S, Narita Y, Mizusawa J, Beppu T, Ogasawara K, Sawamura Y, Kobayashi H, Nishikawa R, Mishima K, Muragaki Y, Maruyama T, Kuratsu J, Nakamura H, Kochi M, Minamida Y, Yamaki T, Kumabe T, Tominaga T, Kayama T, Sakurada K, Nagane M, Kobayashi K, Nakamura H, Ito T, Yazaki T, Sasaki H, Tanaka K, Takahashi H, Asai A, Todo T, Wakabayashi T, Takahashi J, Takano S, Fujimaki T, Sumi M, Miyakita Y, Nakazato Y,
Sato A, Fukuda H, Nomura K: Randomized trial of chemoradiotherapy and adjuvant chemotherapy with nimustine (ACNU) versus nimustine plus procarbazine for newly diagnosed anaplastic astrocytoma and glioblastoma (JCOG0305). Cancer Chemother Pharmacol 71: 511-521, 2013

28) Stupp R, Mason WP, van den Bent MJ, Weller M, Fisher B, Taphoorn MJ, Belanger K, Brandes AA, Marosi C, Bogdahn U, Curschmann J, Janzer RC, Ludwin SK, Gorlia T, Allgeier A, Lacombe D, Cairncross JG, Eisenhauer E, Mirimanoff RO; European Organisation for Research and Treatment of Cancer Brain Tumor and Radiotherapy Groups; National Cancer Institute of Canada Clinical Trials Group: Radiotherapy plus concomitant and adjuvant temozolomide for glioblastoma. N Engl J Med 352: 987-996, 2005

29) Jeswani S, Nuño M, Folkerts V, Mukherjee D, Black KL, Patil CG: Comparison of survival between cerebellar and supratentorial glioblastoma patients: surveillance, epidemiology, and end results (SEER) analysis. Neurosurgery 73: 240-246; discussion 246; quiz 246, 2013

30) Kesari S, Kim RS, Markos V, Drappatz J, Wen PY, Pruitt AA: Prognostic factors in adult brainstem gliomas: a multicenter, retrospective analysis of 101 cases. J Neurooncol 88: 175-183, 2008

31) Semrad TJ, O’Donnell R, Wun T, Chew H, Harvey D, Zhou H, White RH: Epidemiology of venous thromboembolism in 9489 patients with malignant glioma. J Neurosurg 106: 601-608, 2007

32) Cohen J, Houttekier D, Onwuteaka-Philipsen B, Miccinesi G, Addington-Hall J, Kaasa S, Bilsen J, Deliens L: Which patients with cancer die at home? A study of six European countries using death certificate data. J Clin Oncol 28: 2267-2273, 2010

Address reprint requests to: Yoshitaka Narita, $\mathrm{MD}, \mathrm{PhD}$, Department of Neurosurgery and Neuro-Oncology, National Cancer Center Hospital, 5-1-1 Tsukiji, Chuo-ku, Tokyo 104-0045, Japan.

e-mail: yonarita@ncc.go.jp 